\title{
Bagaço de mandioca em dietas de novilhas leiteiras: consumo de nutrientes e desempenho produtivo
}

[Cassava bagasse in diets of dairy heifers: intake of nutrients and productive performance]

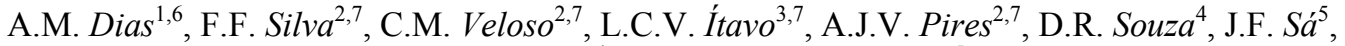 \\ F.B.L. Mendes ${ }^{4}$, P.V. Nunes Nascimento ${ }^{5}$ \\ ${ }^{1}$ Aluno de pós-graduação - UEM - Maringá, PR \\ ${ }^{2}$ Universidade Estadual do Sudoeste da Bahia - Itapetinga, BA \\ ${ }^{3}$ Universidade Católica Dom Bosco - Campo Grande, MS \\ ${ }^{4}$ Aluno de graduação - UESB - Itapetinga, BA \\ ${ }^{5}$ Aluno de pós-graduação - UESB - Itapetinga, BA \\ ${ }^{6}$ Bolsista da FUNDECT \\ ${ }^{7}$ Bolsista do $\mathrm{CNPq}$
}

\begin{abstract}
RESUMO
A inclusão de quatro níveis, $0,7,14$ e 21\%, de bagaço de mandioca na dieta de novilhas leiteiras foi avaliada durante 56 dias. Utilizaram-se 20 novilhas leiteiras 3/4Gir x 1/4Holandês. Os animais foram distribuídos em quatro tratamentos e cinco repetições, recebendo dietas compostas por silagem de sorgo e concentrado, duas vezes ao dia. As dietas foram balanceadas para promover ganho de peso de $0,70 \mathrm{~kg} / \mathrm{dia}$. Realizaram-se pesagens, a cada 28 dias, para determinar o ganho de peso. Avaliaram-se o consumo dos nutrientes, o ganho médio diário (GMD) e a conversão alimentar (CA). O consumo foi expresso em $\mathrm{kg} / \mathrm{dia}$, porcentagem do peso corporal $(\% \mathrm{PC})$ e gramas por $\mathrm{kg}$ de peso metabólico $\left(\mathrm{g} / \mathrm{kg}^{0,75}\right)$. Os consumos de matéria seca e de proteína bruta não foram influenciados pelos tratamentos, mas os consumos de fibra em detergente neutro e de fibra em detergente ácido apresentaram comportamento linear decrescente com o aumento do nível de bagaço; para o consumo de carboidratos não fibrosos, houve aumento linear $(\mathrm{P}<0,10)$. O GMD foi de 0,$84 ; 0,80 ; 0,79$ e $0,51 \mathrm{~kg} /$ dia e a CA de 7,2; 7,5; 8,4 e 12,6 para os tratamentos $0,7,14$ e 21\% de inclusão do bagaço de cana, respectivamente. O melhor nível de utilização de bagaço de mandioca na dieta de novilhas foi $14 \%$.
\end{abstract}

Palavras-chave: novilha leiteira, bagaço de mandioca, consumo, ganho de peso

\section{ABSTRACT}

The inclusion of 0, 7, 14, and 21\% of cassava bagasse in the diet of dairy was evaluated during 56 days. Twenty $3 / 4$ Gir $x 1 / 4$ Holstein heifers were used, being five animals per treatment. The diets were balanced to provide a weight gain of $0.70 \mathrm{~kg} / \mathrm{day}$, and it was measured at every 28 days. Intake of nutrients, average daily weight gain (DWG), and feed conversion $(F C)$ were evaluated. The intake was expressed in $\mathrm{kg} /$ day, body weight percentage (BW\%) and grams for $\mathrm{kg}$ of metabolic weight $\left(\mathrm{g} / \mathrm{kg}^{0.75}\right)$. The intakes of dry matter and crude protein were not affected by the inclusion of cassava bagasse to the diet, but intakes of the neutral detergent fiber and acid detergent fiber linearly decreased with the increase of the cassava bagasse level. However, the intake of non-fiber carbohydrates linearly increased $(P<0.10)$. The DWG was $0.84 ; 0.80 ; 0.79 ;$ and $0.51 \mathrm{~kg} /$ day and the $F C$ was $7.2 ; 7.5 ; 8.4 ;$ and 12.6 for treatments $0,7,14$, and $21 \%$, respectively. The best level of cassava bagasse utilization in diets of heifers was $14 \%$.

Keywords: dairy heifer, cassava bagasse, intake, weight gain

Recebido em 1 de junho de 2007

Aceito em 30 de abril de 2008

E-mail: alezootec@hotmail.com 


\section{INTRODUÇÃO}

Material desclassificado para o consumo humano, o bagaço de mandioca é o resíduo da indústria da mandioca formado após a fabricação do polvilho. Seu teor de matéria seca (MS) é alto, $87,5 \%$, e seu teor de proteína bruta (PB) é muito baixo, $1,9 \%$ da MS. Apresenta baixos teores de fibra em detergente neutro (FDN) e fibra em detergente ácido (FDA), e alto teor de amido, por isso pode ser utilizado em substituição ao milho, por ser considerado como um alimento concentrado.

O consumo de MS é considerado como um dos principais fatores correlacionados a produção de ruminantes, pois na MS estão localizados os nutrientes necessários para suprir as exigências do organismo animal. Silva et al. (2005) não encontraram diferença da inclusão do bagaço de mandioca no consumo de MS em novilhas $3 / 4$ Holandês x 1/4 Zebu confinadas. As proporções de inclusão de bagaço de mandioca, $5,10,15$ e $20 \%$, não interferiram no consumo de $\mathrm{MS}$, sendo de $6,0 \mathrm{~kg} / \mathrm{animal} / \mathrm{dia}$.

Jorge et al. (2002), ao avaliarem o efeito da substituição do milho pela farinha de varredura de mandioca, 0, 25, 50, 75 e $100 \%$, sobre o consumo de nutrientes e desempenho de bezerros da raça Holandesa confinados, verificaram que o consumo de $\mathrm{MS}$, em relação ao peso corporal (PC) dos animais, teve comportamento linear decrescente com o aumento da porcentagem de substituição, 2,4 a $2,2 \%$ do PC. Os autores observaram que houve redução no consumo de PB e FDN, porém não no consumo de amido. A conversão alimentar não foi alterada e, apesar do ganho de peso ter sido menor com a inclusão da farinha de varredura, os valores observados foram satisfatórios.

Ramos et al. (2000), ao testarem o bagaço de mandioca em substituição ao milho no concentrado, 0, 33, 66 e 99\%, para novilhos, observaram que, nas substituições acima de $48,7 \%$ o consumo de MS se reduziu e o consumo máximo de $\mathrm{PB}$ foi de $10,61 \mathrm{~g} / \mathrm{kgPC}^{0,75}$ para a proporção de $43,8 \%$ de substituição do bagaço.

Segundo Mertens (1985), a capacidade ótima para ingestão da FDN é de 1\% do PC para animais em crescimento. Mertens (1987) relatou ser importante que o teor da FDN não limite a ingestão, para que os animais sejam capazes de consumir quantidades suficientes de MS que atendam às suas necessidades energéticas, não influenciando a produção. $\mathrm{O}$ consumo de FDN em níveis acima de $1,2 \%$ do PC do animal (Mertens, 1992) seria um dos principais mecanismos físicos reguladores do consumo de MS.

Silva et al. (2006), ao trabalharem com a proporção de 5, 10, 15 e $20 \%$ de bagaço de mandioca na ensilagem do capim-elefante, observaram que o consumo de MS foi semelhante entre os tratamentos. Expressos em $\mathrm{kg} / \mathrm{dia}, \% \mathrm{PC}$ e g/ $\mathrm{kg}^{0,75}$, o consumo médio de MS foi de 5,56; 3,18 e 115,42, respectivamente, isto é, não ocorreu aumento no consumo de MS com o aumento da inclusão do bagaço na silagem. $\mathrm{O}$ consumo de PB também não diferiu entre os tratamentos e na mesma ordem de citação acima, foi de 0,$70 ; 0,40$ e 14,46. O consumo da FDN, expresso em $\mathrm{kg} /$ dia e \%PC, foi de 2,$60 ; 2,14$; 2,37 e $1,79 \mathrm{~kg} / \mathrm{dia}$ e 1,$54 ; 1,53 ; 1,28$ e $1,05 \% \mathrm{PC}$ para os tratamentos com 5, 10, 15 e 20\%, respectivamente. $\mathrm{O}$ consumo da FDN variou de 1,54 a $1,05 \%$ do PC e não limitou o consumo. $\mathrm{O}$ ganho de peso médio diário (GMD) não diferiu entre tratamento e foi de $1,07 \mathrm{~kg} / \mathrm{dia}$.

A utilização do bagaço de mandioca, em substituição ao milho utilizado no concentrado, $0,33,66,99 \%$, na base da MS, foi avaliada por Ramos et al. (2000) em novilhos em crescimento. Os autores concluíram que o bagaço de mandioca pode ser utilizado em substituição ao milho no concentrado para bovinos em até $66 \%$, sem alterar o GMD e a conversão alimentar (CA). As médias para GMD e CA foram 1,06kg/animal/dia e 5,12, respectivamente.

Este trabalho teve o objetivo de avaliar a proporção de inclusão do bagaço de mandioca na dieta sobre o consumo dos nutrientes e sobre o desempenho de novilhas leiteiras.

\section{MATERIAL E MÉTODOS}

Foram utilizadas 20 novilhas $3 / 4$ Gir x $1 / 4$ Holandês, com PC médio inicial de $180 \mathrm{~kg}$, média de idade 14,5 meses, confinadas em baias individuais. Os animais, após passarem por um período de adaptação de 14 dias, foram pesados e distribuídos em quatro tratamentos (T), 
compostos por quatro diferentes proporções de inclusão de bagaço de mandioca nas dietas, $0 ; 7$; 14 e $21 \%$, em delineamento inteiramente ao acaso, com cinco repetições. No T1 não houve inclusão de bagaço de mandioca na dieta. Nos tratamentos $\mathrm{T} 2, \mathrm{~T} 3$, e T4 a inclusão foi de $7 \%$, $14 \%$ e $21 \%$, respectivamente.

O volumoso utilizado foi silagem de sorgo. As dietas foram calculadas para conter nutrientes suficientes para um ganho de peso corporal médio diário de $0,70 \mathrm{~kg} / \mathrm{dia}$, de acordo com o NRC (Nutrient..., 2001), com base nos dados das análises bromatológicas da silagem previamente realizada no início do período de adaptação.

O teor de nutrientes digestíveis totais (NDT) da silagem foi estimado a partir da equação de regressão descrita por Cappelle et al. (2001), para silagem sem aditivo.

Todas as dietas foram calculadas para serem isoprotéicas e isoenergéticas. As proporções estimadas dos ingredientes nos concentrados são apresentadas na Tab. 1. Para esses cálculos estimativos, foram compiladas da literatura as composições químicas da silagem de sorgo e dos ingredientes do concentrado (Valadares Filho et al., 2001), encontrando-se uma relação volumoso:concentrado de 64:36; 57:43; 50:50 e 43:57, na base da matéria seca, para as dietas com $0,7,14$ e $21 \%$ de bagaço de mandioca na dieta, respectivamente.

Os alimentos, fornecidos duas vezes ao dia, às 7 e $16 \mathrm{~h}$, foram ajustados de forma a manter sobras em torno de 5 a $10 \%$ do fornecido. Foram colhidas, diariamente, amostras de silagem e das sobras por animal e, semanalmente, amostras dos concentrados, por tratamento. As amostras diárias de silagem e das sobras foram agrupadas, de forma proporcional, em cada período de sete dias, constituindo-se em amostras compostas. Todas as amostras foram pré-secas em estufa de ventilação forçada a $55^{\circ} \mathrm{C}$ e moídas em moinho com peneira de malha de $1 \mathrm{~mm}$, para posteriores análises laboratoriais. Os animais foram pesados no início do experimento e, periodicamente, a cada 28 dias, para a determinação do ganho de peso corporal (GPC). O experimento teve duração fixa de 56 dias.

As determinações de matéria seca (MS), matéria orgânica (MO), nitrogênio total, extrato etéreo (EE), fibra em detergente neutro (FDN) e fibra em detergente ácido (FDA) foram realizadas conforme técnicas descritas por Silva e Queiroz (2002). Os carboidratos não-fibrosos (CNF) foram obtidos segundo a equação recomendada por Sniffen et al. (1992).

$\mathrm{Na}$ Tab. 1 apresenta-se a proporção dos ingredientes nos concentrados, na base MS.

Na Tab. 2 encontram-se os teores médios da MS, MO, PB, EE, FDN, FDA, CNF, MM da silagem de sorgo e do bagaço de mandioca.

Teores médios de MS, MO, PB, EE, FDN, FDA, CNF e MM dos concentrados, na base da matéria seca, estão na Tab. 3.

Tabela 1. Proporção dos ingredientes nos concentrados, na base da matéria seca, usados para novilhas

\begin{tabular}{lcccc}
\hline \multirow{2}{*}{\multicolumn{1}{c}{ Ingrediente }} & \multicolumn{3}{c}{ Proporção de bagaço de mandioca na dieta (\%) } \\
\cline { 2 - 5 } & 0 & 7 & 14 & 21 \\
\hline Bagaço de mandioca (\%) & - & 16,25 & 27,95 & 36,8 \\
Milho grão moído (\%) & 67,96 & 55,02 & 45,63 & 38,56 \\
Farelo de soja (\%) & 25,24 & 22,93 & 21,28 & 20,05 \\
Calcário calcítico (\%) & 1,79 & 1,5 & 1,33 & 1,16 \\
Fosfato bicálcico (\%) & 0,81 & 0,8 & 0,81 & 0,79 \\
Sal mineral (\%) & 1,52 & 1,28 & 1,11 & 0,96 \\
Uréia (\%) & 2,32 & 1,94 & 1,68 & 1,49 \\
Sulfato de amônia (\%) & 0,36 & 0,28 & 0,21 & 0,19 \\
\hline
\end{tabular}

${ }^{1}$ Composição: cálcio, 18,5\%; fósforo, $9 \%$; magnésio, 0,4\%; enxofre, 1\%; sódio, 11,7\%; selênio, 30ppm; cobre, 1500ppm; zinco, 4000ppm; manganês, 1200ppm; iodo, 150ppm; cobalto, 150ppm. 
Tabela 2. Teores médios de matéria seca (MS), matéria orgânica (MO), proteína bruta (PB), extrato etéreo (EE), fibra em detergente neutro (FDN), fibra em detergente ácido (FDA), carboidratos não fibrosos (CNF), matéria mineral (MM) e nutrientes digestíveis totais (NDT) do bagaço de mandioca e da silagem de sorgo

\begin{tabular}{lcc}
\hline$(\%)^{1}$ & Bagaço de mandioca & Silagem de sorgo \\
\hline MS & 87,5 & 24,1 \\
MO & 98,4 & 90,7 \\
PB & 1,9 & 6,9 \\
EE & 0,6 & 6,8 \\
FDN & 12,0 & 62,8 \\
FDA & 6,7 & 36,7 \\
CNF $^{2}$ & 83,8 & 14,2 \\
MM & 1,6 & 9,3 \\
NDT & $55,9^{3}$ & $53,8^{4}$
\end{tabular}

${ }^{2}$ Na base da MS.

${ }^{2} \mathrm{CNF}=\mathrm{MO}-\mathrm{PB}-\mathrm{EE}-\mathrm{FDN}$.

${ }^{3}$ NDT do bagaço de mandioca $=$ recomendação de Cappelle et al. (2001) para concentrados.

${ }^{4}$ NDT da silagem = recomendação de Cappelle et al. (2001) para silagem sem aditivo.

Tabela 3. Teores médios de matéria seca (MS), matéria orgânica (MO), proteína bruta (PB), extrato etéreo (EE), fibra em detergente neutro (FDN), fibra em detergente ácido (FDA), carboidratos não fibrosos $(\mathrm{CNF})$ e matéria mineral (MM) de acordo com os tratamentos

\begin{tabular}{lcccc}
$(\%)^{1}$ & T1 & T2 & T3 & T4 \\
\hline MS & 87,8 & 88,4 & 87,8 & 88,2 \\
MO & 81,36 & 82,35 & 82,38 & 83,11 \\
PB & 23,59 & 21,18 & 19,70 & 18,49 \\
EE & 4,72 & 4,76 & 4,32 & 4,04 \\
FDN & 13,63 & 12,40 & 12,31 & 11,35 \\
FDA & 6,90 & 6,20 & 6,74 & 6,64 \\
CNF & 39,42 & 44,01 & 46,05 & 49,23 \\
MM & 6,44 & 6,05 & 5,42 & 5,09 \\
\hline
\end{tabular}

${ }^{1} \mathrm{Na}$ base da MS.

${ }^{2} \mathrm{CNF}=\mathrm{MO}-\mathrm{PB}-\mathrm{EE}-\mathrm{FDN}$.

T1: sem inclusão de bagaço de mandioca na dieta; T2: inclusão de 7\% de bagaço de mandioca na dieta; T3: 14\% de bagaço de mandioca na dieta; T4: $21 \%$ de bagaço de mandioca na dieta.

$\mathrm{Na}$ Tab. 4, encontra-se a relação volumoso:concentrado ( $\mathrm{V}: \mathrm{C})$ das $\operatorname{dietas} \mathrm{e}$ a composição bromatológica das dietas totais fornecidas nos quatro tratamentos. Foram determinados os consumos dos nutrientes, MS, PB, FDN, FDA e NDT, em kg/dia, em \% do PC e por unidade de peso metabólico $\left(\mathrm{g} / \mathrm{kgPC}^{0,75}\right)$ e a conversão alimentar (CA).
Usaram-se análises de variância e de regressão utilizando-se o SAEG (Sistema..., 2001). Os coeficientes de regressão individuais foram testados pelo teste $\mathrm{t}$ a $10 \%$ de probabilidade. 
Tabela 4. Relação volumoso:concentrado (V:C) e teores (\%) de matéria seca (MS), matéria orgânica $(\mathrm{MO})$, proteína bruta $(\mathrm{PB})$, extrato etéreo (EE), fibra em detergente neutro (FDN), fibra em detergente ácido (FDA), carboidratos não fibrosos (CNF), matéria mineral (MM) segundo os tratamentos

\begin{tabular}{lcccc}
\hline & $\mathrm{T} 1$ & $\mathrm{~T} 2$ & $\mathrm{~T} 3$ & $\mathrm{~T} 4$ \\
\hline $\mathrm{V}: \mathrm{C}(\% \mathrm{MS})$ & $64: 36$ & $57: 43$ & $50: 50$ & $43: 57$ \\
\hline $\mathrm{MS}^{1}$ & 47,03 & 50,06 & 55,94 & 60,64 \\
$\mathrm{MO}^{2}$ & 91,76 & 92,13 & 92,66 & 93,12 \\
$\mathrm{~PB}^{1}$ & 12,91 & 13,04 & 13,3 & 13,5 \\
$\mathrm{EE}^{1}$ & 6,08 & 5,95 & 5,59 & 5,24 \\
$\mathrm{FDN}^{1}$ & 45,08 & 41,11 & 37,55 & 33,46 \\
$\mathrm{FDA}^{1}$ & 25,97 & 23,60 & 21,72 & 19,56 \\
$\mathrm{CNF}^{1}$ & 27,69 & 32,03 & 36,22 & 40,92 \\
$\mathrm{MM}^{1}$ & 8,24 & 7,87 & 7,34 & 6,88 \\
\hline
\end{tabular}

${ }^{1} \mathrm{Na}$ base da MS.

${ }^{2} \mathrm{MO}=\mathrm{MS}-\mathrm{MM}$.

T1: sem inclusão de bagaço de mandioca na dieta; T2: inclusão de 7\% de bagaço de mandioca na dieta; T3: 14\% de bagaço de mandioca na dieta; T4: $21 \%$ de bagaço de mandioca na dieta.

\section{RESULTADOS E DISCUSSÃO}

Os consumos médios diários de $\mathrm{MS}, \mathrm{PB}, \mathrm{EE}$, FDN, FDA, CNF em kg/dia, \%PC e g/ $/ \mathrm{kg}^{0,75}$ estão apresentados na Tab. 5.

O consumo de MS, independentemente da forma em que foi expressa, foi semelhante entre os tratamentos. A proporção de bagaço de mandioca não interferiu no consumo de MS. Silva et al. (2006), ao utilizar o bagaço de mandioca na ensilagem do capim-elefante observou que o consumo de MS expresso em kg/dia, em \%PC e $\mathrm{em} \mathrm{g} / \mathrm{kgPC}^{0,75}$ foi, respectivamente, 5,$5 ; 3,18$ e 115,42 , e não houve diferença entre os tratamentos. $\mathrm{O}$ autor também não observou aumento no consumo de MS com o aumento da inclusão do bagaço na silagem. Também Silva et al., (2005), ao incluírem o bagaço de mandioca, não encontraram diferença no consumo de MS em novilhas $3 / 4$ Holandês $\mathrm{x}$ Zebu. As porcentagens de inclusão de bagaço de mandioca, $5,10,15$ e $20 \%$, foram próximas às usadas neste experimento, e o resultado obtido pelos autores foi de $6,0 \mathrm{~kg}$ de $\mathrm{MS} /$ dia, valores semelhantes aos encontrados neste trabalho.

Jorge et al. (2002), ao trabalharem com bezerros da raça Holandesa e avaliarem a proporção de substituição da farinha de varredura pelo milho, observaram que o consumo de $\mathrm{MS}$ foi de $2,7 \% \mathrm{PC}$ e $97,4 \mathrm{~g} / \mathrm{kgPC}^{0,75}$ e que não houve diferença entre os tratamentos. Vale ressaltar que a dieta apresentou relação de $20 \%$ de volumoso e
$80 \%$ de concentrado. Neste trabalho os valores de consumo foram mais elevados, 3,05\% $\mathrm{PC}$, visto que o bagaço de mandioca não limitou $\mathrm{o}$ consumo e as novilhas puderam expressar todo o seu potencial de ingestão de MS. Esse consumo pode ser atribuído à menor proporção de concentrado na dieta e ao maior PC das novilhas.

Ramos et al. (2000), ao estudarem o bagaço de mandioca como substituto do milho no concentrado de novilhos, verificaram que substituição maior que $48,7 \%$ resulta em redução do consumo de MS. O valor máximo de consumo encontrado foi de $88,53 \mathrm{~g} / \mathrm{kgPC}^{0,75}$, menor que o encontrado no presente trabalho, de $121,71 \mathrm{~g} / \mathrm{kgPC}^{0,75}$.

O consumo de PB não foi influenciado pela proporção de bagaço de mandioca na dieta. Caldas Neto et al. (2000) estudaram o consumo de $\mathrm{PB}$ em novilhos alimentados com dietas à base de silagem de milho com casca e com raspa de mandioca desidratada com $14 \%$ de $\mathrm{PB}$ e verificaram consumo de $\mathrm{PB}$ de $0,20 \%$ do PC, valor mais baixo que o encontrado neste trabalho para consumo de PB. Apesar de as novilhas terem apresentado o mesmo consumo de PB, quando se elevou a proporção de bagaço de mandioca, o GMD se reduziu, o que resultou em menor desempenho. Os animais dos tratamentos com maior inclusão de bagaço de mandioca consumiram maior quantidade de concentrado. 
Tabela 5. Consumos de matéria seca (MS), proteína bruta (PB), extrato etéreo (EE), fibra em detergente neutro (FDN), fibra em detergente ácido (FDA) e carboidratos não fibrosos (CNF) de novilhas leiteiras que receberam dietas com diferentes proporções de bagaço de mandioca PBM na dieta e respectivas equações de regressão (ER)

\begin{tabular}{|c|c|c|c|c|c|c|c|}
\hline & T1 & $\mathrm{T} 2$ & T3 & $\mathrm{T} 4$ & CV (\%) & $\mathrm{P}$ & ER \\
\hline & \multicolumn{4}{|c|}{ MS } & & & \\
\hline $\mathrm{kg} / \mathrm{dia}$ & 5,90 & 5,82 & 6,39 & 6,07 & 13,66 & NS & $\hat{\mathrm{Y}}=6,04$ \\
\hline$\% \mathrm{PC}$ & 3,01 & 2,82 & 3,24 & 3,06 & 10,09 & NS & $\hat{\mathrm{Y}}=3,03$ \\
\hline \multirow[t]{2}{*}{$\mathrm{g} / \mathrm{kgPC}^{0,75}$} & 112,60 & 107,14 & 121,71 & 115,09 & 10,09 & NS & $\hat{\mathrm{Y}}=114,13$ \\
\hline & \multicolumn{4}{|c|}{$\mathrm{PB}$} & & & \\
\hline $\mathrm{kg} / \mathrm{dia}$ & 0,737 & 0,732 & 0,831 & 0,804 & 12,78 & 0,1502 & $\hat{\mathrm{Y}}=0,776$ \\
\hline$\% \mathrm{PC}$ & 0,37 & 0,35 & 0,40 & 0,40 & 9,665 & NS & $\hat{\mathrm{Y}}=0,373$ \\
\hline \multirow[t]{2}{*}{$\mathrm{g} / \mathrm{kgPC}^{0,75}$} & 7,29 & 6,58 & 8,09 & 7,71 & 13,67 & NS & $\hat{\mathrm{Y}}=7,41$ \\
\hline & \multicolumn{4}{|c|}{ FDN } & & & \\
\hline $\mathrm{kg} / \mathrm{dia}$ & 2,57 & 2,27 & 2,26 & 1,85 & 14,60 & 0,0241 & 1 \\
\hline$\% \mathrm{PC}$ & 1,31 & 1,10 & 1,14 & 0,93 & 10,21 & 0,0002 & 2 \\
\hline \multirow[t]{2}{*}{$\mathrm{g} / \mathrm{kgPC}^{0,75}$} & 25,43 & 20,46 & 22,08 & 17,77 & 13,94 & 0,0025 & 3 \\
\hline & \multicolumn{4}{|c|}{ FDA } & & & \\
\hline $\mathrm{kg} / \mathrm{dia}$ & 1,47 & 1,31 & 1,35 & 1,18 & 14,08 & 0,1458 & 4 \\
\hline$\% \mathrm{PC}$ & 0,75 & 0,63 & 0,68 & 0,59 & 9,94 & 0,0065 & 5 \\
\hline \multirow[t]{2}{*}{$\mathrm{g} / \mathrm{kgPC}^{0,75}$} & 14,55 & 11,85 & 13,24 & 11,34 & 13,67 & 0,0315 & 6 \\
\hline & \multicolumn{4}{|c|}{$\mathrm{CNF}$} & & & \\
\hline $\mathrm{kg} / \mathrm{dia}$ & 1,53 & 1,72 & 2,24 & 1,95 & 17,29 & 0,0137 & 7 \\
\hline$\% \mathrm{PC}$ & 0,78 & 0,83 & 1,13 & 0,98 & 12,27 & 0,0012 & 8 \\
\hline $\mathrm{g} / \mathrm{kgPC}^{0,75}$ & 29,21 & 31,64 & 42,49 & 36,84 & 12,96 & 0,0018 & 9 \\
\hline \multicolumn{3}{|c|}{$\begin{array}{l}\text { T1: sem inclusão de bagaço de mandioca na dieta; T2: } \\
\text { inclusão de } 7 \% \text { de bagaço de mandioca na dieta; T3: } \\
14 \% \text { de bagaço de mandioca na dieta; T4: } 21 \% \text { de } \\
\text { bagaço de mandioca na dieta. PC: peso corporal. P: } \\
\text { probabilidade }\end{array}$} & \multirow{4}{*}{\multicolumn{5}{|c|}{$\begin{array}{l}\text { 5. }\left(\mathrm{R}^{2}=0,64\right), \hat{Y}_{\mathrm{i}}=0,7333-0,00597 * \mathrm{PBM} \\
\text { 6. }\left(\mathrm{R}^{2}=0,54\right), \hat{Y}_{\mathrm{i}}=13,9803-0,1174 * \mathrm{PBM} \\
\text { 7. }\left(\mathrm{R}^{2}=0,56\right), \hat{Y}_{\mathrm{i}}=1,5942+0,0254 * \mathrm{PBM} \\
\text { 8. }\left(\mathrm{R}^{2}=0,54\right), \hat{Y}_{\mathrm{i}}=0,7991+0,0128 * \mathrm{PBM} \\
\text { 9. }\left(\mathrm{R}^{2}=0,55\right), \hat{Y}_{\mathrm{i}}=29,9871+0,4822 * \mathrm{PBM} \\
\text { *Significância das equações de regressão }(\mathrm{P}<0,05)\end{array}$}} \\
\hline \multicolumn{3}{|c|}{ 1. $\left(\mathrm{R}^{2}=0,90\right), \hat{Y}_{\mathrm{i}}=2,57258-0,0312 * \mathrm{PBM}$} & & & & & \\
\hline \multicolumn{3}{|c|}{ 2. $\left(\mathrm{R}^{2}=0,82\right), \hat{Y}_{\mathrm{i}}=1,29257-0,0156 * \mathrm{PBM}$} & & & & & \\
\hline \multicolumn{3}{|c|}{ 3. $\left(\mathrm{R}^{2}=0,74\right), \hat{Y}_{\mathrm{i}}=24,6471-0,3053 * \mathrm{PBM}$} & & & & & \\
\hline \multicolumn{3}{|c|}{ 4. $\left(\mathrm{R}^{2}=0,80\right), \hat{Y}_{\mathrm{i}}=1,4600-0,01196 * \mathrm{PBM}$} & & & & & \\
\hline
\end{tabular}

$\mathrm{O}$ consumo de FDN, expresso em $\mathrm{kg} / \mathrm{dia}$, \% PC ou $\mathrm{g} / \mathrm{kgPC}^{0,75}$, apresentou comportamento linear decrescente com o aumento de bagaço de mandioca, pois ao reduzir a proporção de volumoso da dieta, ingrediente que contém alto teor de fibra, elevou-se à quantidade de CNF da dieta. Assim, o teor de FDN não influenciou o consumo de MS da dieta. Este comportamento linear negativo do consumo de FDN é atribuído à diminuição na relação volumoso:concentrado, de 64:36; 57:43; 50:50 e 43:57\%, na base da MS, para os tratamentos com $0,7,14$ e $21 \%$ de inclusão de bagaço de mandioca na dieta, respectivamente. Os animais do $\mathrm{T} 4$ recebiam maior quantidade de concentrado para atender às suas exigências nutricionais e para obterem ganhos de $0,70 \mathrm{~kg} / \mathrm{dia}$, como recomendado pelo NRC (Nutrient..., 2001).

O consumo de FDN não limitou o consumo de MS, mas pode ter influenciado no desempenho dos animais (Tab. 6). Martins (1999) verificou valores de 0,8 e $1,2 \%$ do PC para dietas que continham silagem de milho associada com casca de mandioca e levedura ou farelo de algodão, respectivamente, em novilhas confinadas. 
$\mathrm{O}$ resultado de ingestão de FDN em T1 mostrou que os animais ingeriram acima de sua capacidade considerada ótima, o que, segundo Mertens (1987), é de 1\% do PC para animais em crescimento. Vale lembrar, é importante que o teor de FDN não limite a ingestão para que os animais sejam capazes de consumir quantidade suficiente de MS que atenda às suas necessidades energéticas e que não afete a produção. $\mathrm{O}$ consumo de FDN acima de $1,2 \%$ do PC do animal (Mertens, 1992) seria um dos principais mecanismos físicos reguladores do consumo de MS, visto que os níveis de FDN, neste trabalho, não limitaram o consumo de MS. Silva et al. (2002), ao trabalharem com novilhos Nelore na fase de recria e engorda, concluíram que o valor de consumo da FDN com relação a \%PC pode ser mais flexível.

Como a FDN geralmente fermenta e passa pelo rúmen-retículo mais lentamente que os outros constituintes da dieta, pode, dessa forma, apresentar maior efeito de enchimento, e isto pode ser considerado como um dos melhores limitadores de ingestão voluntária de MS. Neste trabalho, o teor de FDN da dieta não influenciou $(\mathrm{P}>0,05)$ o consumo de MS na fase de crescimento das novilhas, pois o consumo de MS apresentou-se elevado, acima de 2,8\%PC. Silva et al. $(2006 ; 2007)$ também observaram redução linear decrescente no consumo de FDN quando se adicionou bagaço de mandioca na ensilagem do capim-elefante e cujos valores foram próximos ao do presente experimento. $\mathrm{O}$ consumo de FDN variou de 1,5 a 1,0\% PC quando se trabalhou com a inclusão de 5, 10, 15 e $20 \%$ de bagaço de mandioca na ensilagem de capim-elefante não limitando o consumo.

$\mathrm{O}$ consumo de FDA expresso em $\mathrm{kg} / \mathrm{dia}$, \% PC e $\mathrm{g} / \mathrm{kg}^{0,75}$, apresentou comportamento linear decrescente com o aumento da proporção de bagaço, devido à redução da FDA na dieta. Os teores de FDA não influenciaram o consumo de MS da dieta.

A ingestão de CNF, apresentou comportamento linear crescente, com a elevação da proporção de bagaço de mandioca, e isto se deveu à maior quantidade de CNF.

Os pesos corporais inicial e final, o ganho de peso total (GPT), o ganho de peso médio diário (GMD) e a conversão alimentar (CA) são apresentados na Tab. 6 .

Tabela 6. Peso corporal inicial (PCi), peso corporal final (PCf), ganho de peso total durante todo o período experimental (GPT), ganho de peso médio diário (GMD) e conversão alimentar (CA) de novilhas leiteiras que receberam dietas com diferentes proporções de bagaço de mandioca (PBM) na dieta

\begin{tabular}{lcccccc}
\hline & $\mathrm{T} 1$ & $\mathrm{~T} 2$ & $\mathrm{~T} 3$ & $\mathrm{~T} 4$ & $\mathrm{CV}(\%)$ & $\mathrm{P}$ \\
\hline $\mathrm{PCi}(\mathrm{kg})$ & 173,4 & 184,6 & 176,2 & 184,6 & 13,24 & - \\
$\mathrm{PCf}(\mathrm{kg})$ & 218,12 & 227,24 & 218,16 & 211,96 & 8,73 & - \\
\hline $\mathrm{GPT}^{1}(\mathrm{~kg})$ & 44,72 & 42,64 & 41,96 & 27,36 & 24,83 & 0,0153 \\
$\mathrm{GMD}^{2}(\mathrm{~kg} / \mathrm{dia})$ & 0,84 & 0,80 & 0,79 & 0,51 & 24,73 & 0,0145 \\
$\mathrm{CA}^{3,4}$ & 7,20 & 7,53 & 8,40 & 12,68 & 26,22 & 0,0020 \\
\hline
\end{tabular}

T1: sem inclusão de bagaço de mandioca na dieta; T2: inclusão de 7\% de bagaço de mandioca na dieta; T3: 14\% de bagaço de mandioca na dieta; T4: $21 \%$ de bagaço de mandioca na dieta. P: probabilidade

${ }^{1}\left(\mathrm{R}^{2}=0,73\right), \mathrm{GPT}: \hat{Y}_{\mathrm{i}}=47,084-0,7537 * \mathrm{PBM}$ (nível de bagaço de mandioca).

${ }^{2}\left(\mathrm{R}^{2}=0,74\right)$, GMD: $\hat{Y}_{\mathrm{i}}=0,8898-0,01431 * \mathrm{PBM}$.

${ }^{3}\left(\mathrm{R}^{2}=0,78\right), \mathrm{CA}: \hat{Y}_{\mathrm{i}}=6,36229+0,247148 * \mathrm{PBM}$.

${ }^{4} \mathrm{~kg}$ consumido $\mathrm{MS} / \mathrm{kg}$ de ganho.

*Significância das equações de regressão $(\mathrm{P}<0,05)$.

GPT e GMD foram influenciadas pelos tratamentos. Houve efeito linear decrescente no desempenho das novilhas quando se aumentou o nível de inclusão de bagaço de mandioca na dieta. $\mathrm{O}$ tratamento sem bagaço de mandioca foi o que resultou em maior ganho de peso, e T2 e
T3 apresentaram valores semelhantes. T4 foi o que apresentou o menor ganho de peso, abaixo do ganho esperado que era de, $0,70 \mathrm{~kg} / \mathrm{dia}$. Desse modo, pode-se inferir que a proporção de $21 \%$ de bagaço de mandioca prejudicou o desempenho esperado das novilhas. Segundo Petitclerc et al. 
(1984), citados por Santos et al. (2002), novilhas leiteiras com ganhos de peso acima de $0,80 \mathrm{~kg} / \mathrm{dia}$, concentram maior quantidade de tecido adiposo na glândula mamária, e isto pode reduzir a produção de leite na primeira lactação e, também nas lactações subseqüentes.

No T4 o GMD foi de $0,51 \mathrm{~kg} /$ dia. Esse desempenho retardaria a entrada do animal na fase reprodutiva, pois demoraria mais tempo para ele alcançar o peso ideal de concepção, que seria de 320kg de PC (Santos e Damasceno, 1999). Este GMD corresponderia a mais 280 dias de confinamento, enquanto as novilhas dos demais tratamentos permaneceriam apenas 175 dias em confinamento.

Com relação à CA, houve aumento linear crescente, quando se aumentou o nível de bagaço de mandioca na dieta. O T4 foi o que apresentou a pior CA $(12,68)$, provavelmente devido à qualidade do amido do bagaço de mandioca.

Em algumas novilhas do T4, no decorrer do experimento, ocorreram casos clínicos de acidose provocando timpanismo, o que poderia ter interferido no GMD e na CA. Marques et al. (2000) sugeriram mais estudos ao se trabalhar com resíduos de indústrias de processamento da mandioca, para evitar problemas de consumo e acidose.

Há de se destacar que, neste experimento, quando se trabalhou com $21 \%$ de inclusão de bagaço de mandioca, a substituição do milho foi de $43 \%$, valor mais baixo que o recomendado por Ramos et al. (2000). Esses autores verificaram que acima de $45 \%$ de substituição do milho, o consumo de MS se reduz, o que não aconteceu no presente trabalho com as proporções estudadas.

O nível de inclusão de até $14 \%$ de bagaço de mandioca não prejudicou no desempenho das novilhas, constatando-se que mostraram boa condição corporal para a reprodução precoce.

\section{CONCLUSÃO}

O nível de inclusão de bagaço de mandioca na dieta de novilhas leiteiras em até $14 \%$ não prejudica o consumo de nutrientes nem o seu desempenho.

\section{REFERÊNCIAS BIBLIOGRÁFICAS}

CALDAS NETO, S.F.; ZEOULA, L.M.; BRANCO A.F. Mandioca e resíduos das farinheiras na alimentação de ruminantes: digestibilidade total e parcial. Rev. Bras. Zootec., v.29, p.2099-2108, 2000.

CAPPELLE, E.R.; VALADARES FILHO, S.C.; SILVA, J.F.C. et al. Estimativas do valor energético a partir de características químicas e bromatológicas dos alimentos. Rev. Bras. Zootec., v.30, p.1837-1856, 2001.

JORGE, J.R.V.; ZEOULA, L.M.; PRADO, I.N. et al. Substituição do milho pela farinha de varredura (Manihot esculenta, Crantz) na ração de bezerros holandeses. 2. Digestibilidade e valor energético. Rev. Bras. Zootec., v.31, p.205-212, 2002.

MARQUES, J.A.; PRADO, I.N.; ZEOULA, L.M. et al. Avaliação da mandioca e seus resíduos industriais em substituição ao milho no desempenho de novilhas confinadas. Rev. Bras. Zootec., v.29, p.1528-1536, 2000.

MARTINS, A.S. Efeito de rações diferenciadas pelo ritmo de degradação ruminal sobre o desempenho de novilhas confinadas. 1999. 84f. Dissertação (Mestrado) - Universidade Estadual de Maringá, Paraná.

MERTENS. D.R. Factors influencing feed intake in lactating cows: from theory to application using neutral detergent fiber. In: NUTRITION CONFERENCE, 46., 1985, Athens. Proceedings... Athens: University of Georgia, 1985. p.1-18.

MERTENS. D.R. Predicting intake and digestibility using mathematical models of ruminal function. J. Anim. Sci., v.641, p.15481558, 1987.

MERTENS, D.R. Análise da fibra e sua utilização na avaliação de alimentos e formulação de rações. In: SIMPÓSIO INTERNACIONAL DE RUMINANTES, 1992, Lavras. Anais... Lavras: SBZ, 1992. p.188-219.

NUTRIENT requirements of dairy cattle. 7.ed. Washington, DC: National Academy of Sciences, 2001. 381p.

PETITCLERC, D; CHAPIN, L.T.; TUCKER, H.A. Carcass composition and mammary development responses to photoperiod and plane 
of nutrition in Holsteins heifers. J. Dairy Sci., v.58, p.913-921, 1984

RAMOS, P.R.; PRATES, E.R.; FONTANELLI, R.S. et al. Uso do bagaço de mandioca em substituição ao milho no concentrado para bovinos em crescimento. 2. Digestibilidade aparente, consumo de nutrientes digestíveis, ganho de peso e conversão alimentar. Rev. Bras. Zootec., v.29, p.300-305, 2000.

SANTOS, G.T.; DAMASCENO, J.C. Nutrição e alimentação de bezerras e novilhas. In: NUTRIÇÃO DE GADO DE LEITE, 1999, Belo Horizonte. Anais... Belo Horizonte: EV-UFMG, 1999. p.39-64.

SANTOS, G.T.; DAMASCENO, J.C.; MASSUDA, E.M. et al. Importância do manejo e considerações econômicas na criação de bezerras e novilhas. In: SIMPÓSIO SOBRE SUSTENTABILIDADE DA PECUÁRIA LEITEIRA NA REGIÃO SUL DO BRASIL. 2., 2002, Toledo. Anais... Maringá: UEM/CCA/DZO - NUPEL, 2002, p.212.

SILVA, D.J.; QUEIROZ, A.C. Análise de alimentos: métodos químicos e biológicos. 3.ed. Viçosa: UFV, 2002. 235p.

SILVA, F.F.; VALADARES FILHO, S.C., ITAVO, L.C.V. et al. Desempenho produtivo de novilhos Nelore, na recria e na engorda, recebendo dietas com diferentes níveis de concentrado e proteína. Rev. Bras. Zootec., v. 31, supl., p.492-502, 2002.

SILVA, R.R.; SILVA, F.F.; CARVALHO, G.G.P. et al. Comportamento ingestivo de novilhas mestiças Holandês x Zebu confinadas. Arch. Zootec., v.54, p.75-85, 2005.

SILVA, F.F.; AGUIAR, M.S.M.A.; VELOSO, C.M. et al. Desempenho de novilhas leiteiras alimentadas com silagem de capim-elefante com adição de diferentes níveis de bagaço de mandioca. Arq. Bras. Med. Vet. Zootec., v.58, p.205-211, 2006.

SILVA, F.F.; AGUIAR, M.S.M.A.; VELOSO, C.M. et al. Bagaço de mandioca na ensilagem do capim-elefante: qualidade das silagens e digestibilidade dos nutrientes. Arq. Bras. Med. Vet. Zootec., v.59, p.711-718, 2007.

SISTEMA de análises estatísticas e genéticas SAEG. Viçosa: UFV, 2001.

SNIFFEN, C.J.; O'CONNOR, J.D.; VAN SOEST, P.J. et al. A net carbohydrate and protein system for evaluating cattle diets. 2 . Carbohydrate and protein availability. J. Anim. Sci., v.70, p.3562-3577, 1992.

VALADARES FILHO, S.C.; ROCHA Jr., V.R.; CAPPELLE, E.R. Tabelas brasileiras de composição de alimentos para bovinos. Viçosa: UFV; 2001. 297p. 